\title{
INFECÇÃO DO TRATO URINÁRIO EM GESTANTES: INCIDÊNCIA E PERFIL DE SUSCETIBILIDADE
}

\author{
Yáskara Gorczevski PIGOSSO, Claudinei Mesquita da SILVA \& Leyde Daiane de PEDER* \\ Centro Universitário da Fundação Assis Gurgacz. Cascavel, Paraná, Brasil. \\ *Autor para correspondência: leydepeder@yahoo.com.br. \\ http://dx.doi.org/10.18571/acbm.099
}

\section{RESUMO}

Na gestação, a infecção do trato urinário (ITU) é de grande importância em função de sua elevada incidência nesse período de vida da mulher. O presente estudo teve por objetivos conhecer a incidência de ITUs em gestantes da cidade de Missal - PR, os fatores de suscetibilidade, assim como os principais agentes etiológicos envolvidos e sua sensibilidade aos antimicrobianos. Foram realizadas análises físicas, químicas, microscópicas, identificação bioquímica de bactérias, quando presentes, e antibiograma em amostras de urina de 50 gestantes. Verificou-se que 9 (18\%) apresentaram infecção urinária, sendo destas, 5 (55,5\%) assintomáticas. O principal patógeno responsável pelas infecções foi Escherichia coli, seguida de Enterococcus faecalis e Streptococcus agalactiae. O estudo revela a grande importância do diagnóstico precoce e tratamento adequado das ITUs, evitando assim, complicações à gestante e ao futuro concepto.

Palavras chave: Gestação; Epidemiologia; Cistite; Pielonefrite.

\begin{abstract}
In pregnancy, urinary tract infection (UTI) is of great importance, due to its high incidence in this period of a woman's life. This study aimed to know the incidence of UTIs in pregnant women from Missal - PR, susceptibility factors, as well as the main etiological agents involved and their antimicrobial susceptibility. Physical, chemical, and microscopic analyses were performed, biochemical identification of bacteria, when present, and sensitivity in 50 pregnant women urine samples. It was found that $9(18 \%)$ of pregnant women had a urinary tract infection, and of which $5(55.5 \%)$ asymptomatic. The main pathogen responsible for infections was Escherichia coli, followed by Enterococcus faecalis and Streptococcus agalactiae. The study reveals the importance of early diagnosis and appropriate treatment of UTIs in pregnant women, thus avoiding complications to the mother and fetus future.
\end{abstract}

Keywords: Pregnancy; Epidemiology; Cystitis; Pyelonephritis.

\section{Introdução}

As infecções do trato urinário (ITUs) correspondem ao crescimento e multiplicação de bactérias nos órgãos do sistema urinário, provocando lesões de graus variáveis. Essas infecções podem ser agrupadas em quatro entidades clínicas diferentes, de acordo com a localização anatômica do agravo, mantendo, todavia, relações entre as mesmas: bacteriúria assintomática (BA), uretrite, cistite e pielonefrite (DUARTE et al., 2008). Sendo a bacteriúria assintomática a entidade clínica mais frequente (2-10\%), seguida da cistite aguda (1-1,5\%) e da pielonefrite aguda (0,5-2\%) (FIGUEIREDO et al., 2012). 


\section{Biomedica Brasiliensia}

As ITUs são classificadas quanto à localização, podendo ser baixas ou altas. As baixas referem-se a infecções que acometem a bexiga e a uretra e são denominadas cistites. As altas podem acometer os rins e as cavidades pielocaliciais ou simultaneamente, os rins, cavidades pielocaliciais, bexiga e uretra, também chamadas pielonefrites. Quanto à gravidade, podem ser complicadas ou não complicadas. São complicadas quando agridem um sistema urinário com alterações estruturais ou funcionais e não complicadas quando investem em um sistema urinário previamente normal (CARVALHO, 2002).

As infecções do trato urinário não complicadas, adquiridas na comunidade, constituem atualmente as patologias mais comuns em mulheres nos Estados Unidos, com mais de oito milhões de consultas por ano, sendo também, significante causa de morbidade e responsáveis por elevados custos em saúde (GUPTA et al., 2001). No Brasil, as ITUs são consideradas as mais comuns das infecções bacterianas, e são responsáveis por 80 em cada 1.000 consultas clínicas (DALBOSCO et al., 2003).

$\mathrm{Na}$ gestação, a infecção urinária é de grande importância em função de sua elevada incidência neste período de vida da mulher. É a terceira intercorrência clínica mais comum na gestação, acometendo de 10 a 12\% das grávidas (JACOCIUNAS e PICOLI, 2007). Além disso, está associada a uma maior incidência de nascimentos de crianças prematuras e/ou de baixo peso, assim como, uma maior mortalidade perinatal e maior morbidade materna (HEILBERG e SCHOR, 2003).

Não raro, infecções significativas envolvendo o trato urinário podem estar presentes em pacientes que não apresentam nenhuma sintomatologia típica. Uma vez que essas infecções podem causar sérios danos renais, caso permaneçam sem tratamento, muitos médicos consideram prudente solicitar testes para detecção de bacteriúria em indivíduos com alto risco. Entre esses, estão os pacientes idosos, as grávidas, os diabéticos e aqueles com história prévia de infecções do trato urinário (MCPHERSON e PINCUS, 2012).

Vários fatores tornam a infecção do trato urinário uma relevante complicação do período gestacional, agravando tanto o prognóstico materno (CONDE-AGUDELO et al., 2008), quanto o perinatal (MCDERMOTT et al., 2000). A preocupação adicional para os profissionais responsáveis pela atenção pré-natal destas mulheres é que, além da incidência aumentada de infecções sintomáticas entre grávidas, o arsenal terapêutico antimicrobiano e as possibilidades profiláticas são restritos, considerando-se a toxicidade de alguns fármacos para o embrião/feto e placenta. Por estes motivos, o conjunto do diagnóstico precoce, seguido de terapêutica adequada e imediata é imprescindível durante a assistência pré-natal, evitando comprometer o prognóstico materno e gestacional (DUARTE et al., 2006).

Sendo assim, o presente estudo teve por objetivos ampliar os conhecimentos a respeito dessa patologia, determinando sua incidência, fatores de suscetibilidade, agentes etiológicos responsáveis e sua sensibilidade aos antimicrobianos em gestantes na cidade de Missal/PR. O trabalho buscou ainda, contribuir para uma melhor abordagem do tema pelos profissionais que atuam na área da saúde e ressaltar a importância do diagnóstico precoce e tratamento adequado.

\section{Materiais e Métodos}

A pesquisa desenvolveu-se com a participação de 50 gestantes da cidade de Missal/PR. As voluntárias foram instruídas verbalmente e através de informações impressas quanto ao procedimento correto para a coleta da amostra de urina a ser utilizada nas análises. Após a obtenção das amostras aplicou-se, para cada voluntária, um questionário simples para adquirir informações individuais. Dados como idade, período da gestação na qual se encontra, paridade e sintomatologia aparente relacionada à infecção do trato urinário foram relatadas.

Cada amostra foi submetida à análise física, bioquímica e microscópica. Para os resultados encontrados alterados, ou seja, com quantidade elevada de leucócitos no teste 
bioquímico e/ou microscópico, bacteriúria moderada à intensa ou ainda para as amostras que apresentaram nitrito positivo, realizou-se a coloração de Gram e cultura das mesmas. Para a urocultura utilizou-se os meios CLED e MacConkey, os quais depois de semeados permaneceram em estufa à $37^{\circ} \mathrm{C}$ por 24 horas.

As amostras positivas, com crescimento microbiano superior a $100.000 \mathrm{UFC} / \mathrm{ml}$, foram submetidas à identificação bioquímica de acordo com suas características morfotintoriais. Para identificação de bacilos Gram-negativos (BGN) utilizou-se o kit de identificação para enterobactérias, composto pelos meios de cultura Rugai, LMI, MIO, Rhamnose e Citrato. Na presença de cocos Gram-positivos (CGP) realizou-se o teste da catalase e identificação bioquímica automatizada no aparelho BD Phoenix.

Os antimicrobianos utilizados no antibiograma foram selecionados conforme padronização do Clinical and Laboratory Standards Institute (CLSI), o qual indica o medicamento de acordo com o agente etiológico responsável pela infecção. Para o teste de sensibilidade aos antimicrobianos (TSA), preparou-se um inóculo equivalente ao tubo 0,5 da escala McFarland com as respectivas colônias isoladas e semeou-as em Ágar Müeller Hinton. Os antibióticos selecionados foram inseridos no meio e mantidos em estufa à $37^{\circ} \mathrm{C}$ por 24 horas. Os níveis de resistência foram propostos de acordo com os limites padronizados pelo CLSI.

As voluntárias que aceitaram participar da pesquisa assinaram o Termo de Consentimento Livre e Esclarecido e o estudo teve início após a aprovação pelo Comitê de Ética em Pesquisa em Humanos do Centro Universitário da Fundação Assis Gurgacz, sob o protocolo de número 072/2013.

\section{Resultados}

De acordo com o resultado do questionário aplicado às voluntárias, o perfil de grande parte das gestantes estudadas foi de mulheres primigestas $(60 \%)$, com média de idade de 25 anos (entre 14 e 40 anos), estando à maioria no primeiro trimestre da gestação (48\%) e sem apresentar quadro prévio de infecção do trato urinário (64\%).

Entre as 50 gestantes que participaram da pesquisa, amostras de 9 apresentaram-se positivas mediante a realização da urocultura, representando $18 \%$ de casos de ITU. Além da porcentagem consideravelmente alta de ITUs encontradas no grupo estudado, $10 \%$ (5) das gestantes eram assintomáticas, ou seja, não manifestaram nenhum sinal e/ou sintoma característico da doença.

Quanto ao perfil do grupo de gestantes que contraíram infecção, demonstrado na Tabela 1, observa-se uma prevalência em mulheres primigestas $(66,67 \%)$ na faixa etária dos 21 a 30 anos de idade $(44,44 \%)$ e sem ocorrência precedente de ITU $(66,67 \%)$.

Além disso, é observado um número crescente de ITUs conforme a idade gestacional, ou seja, houve maior incidência de infecções urinárias durante o terceiro trimestre da gestação $(44,44 \%)$ quando comparadas ao segundo trimestre $(33,33 \%)$, e ao primeiro $(22,22 \%)$.

No exame físico das amostras de urinas das gestantes acometidas por ITU, o volume médio observado foi de $40 \mathrm{ml}$, com pH 7,0 em 11,11\% dos casos, pH 6,5 em 22,22\% e urina discretamente ácida (pH 5,5 a 6,0) em 66,67\% dos casos. Densidade de 1.010 foi observada em 2 amostras (22,22\%), e acima disso, entre 1.015 e 1.025, em 7 amostras (77,78\%). Quanto ao aspecto, duas amostras $(22,22 \%)$ apresentaram-se turvas e sete $(77,78 \%)$ ligeiramente turvas, nenhuma apresentou aspecto límpido. A maioria possuía coloração amarelo citrino $(66,67 \%)$, seguida de amarelo claro $(33,33 \%)$. 
Tabela 1: Dados referentes às gestantes portadoras de ITU

\begin{tabular}{|c|c|c|}
\hline Dados & & $\%$ (Quantidade) \\
\hline Idade & $\begin{array}{l}\text { Até } 20 \text { anos } \\
21 \text { a } 30 \text { anos } \\
31 \text { a } 40 \text { anos }\end{array}$ & $\begin{array}{l}33,33 \%(3) \\
44,44 \%(4) \\
22,22 \%(2)\end{array}$ \\
\hline Paridade & $\begin{array}{c}1 \\
2 \\
3 \text { ou mais }\end{array}$ & $\begin{array}{l}66,67 \%(6) \\
22,22 \%(2) \\
11,11 \%(1)\end{array}$ \\
\hline Trimestre da gestação & $\begin{array}{l}\text { Primeiro } \\
\text { Segundo } \\
\text { Terceiro }\end{array}$ & $\begin{array}{l}22,22 \%(2) \\
33,33 \%(3) \\
44,44 \%(4)\end{array}$ \\
\hline $\begin{array}{r}\text { Presença de sinais e/ou sintomas característicos de } \\
\text { ITU }\end{array}$ & $\begin{array}{l}\text { Sim } \\
\text { Não }\end{array}$ & $\begin{array}{l}44,44 \%(4) \\
55,56 \%(5)\end{array}$ \\
\hline Casos anteriores de ITU & $\begin{array}{l}\text { Sim } \\
\text { Não }\end{array}$ & $\begin{array}{l}33,33 \%(3) \\
66,67 \%(6)\end{array}$ \\
\hline
\end{tabular}

O teste de esterase leucocitária obteve concordância de 77,78\% em relação às uroculturas positivas. Sendo assim, dois casos com presença de infecção urinária não apresentaram alteração leucocitária no teste bioquímico com fita reagente, apesar de em ambos ter sido constatado considerável aumento do número de leucócitos no exame microscópico e presença de nitrito positivo. Por outro lado, das 41 amostras sem infecção, 4 delas $(9,75 \%)$ mostraram-se com número de leucócitos aumentados e $1(2,43 \%)$ obteve nitrito positivo.

No exame microscópico, foram verificadas 14 amostras com alteração leucocitária (28\%), sendo que entre estas, 9 possuíam infecção do trato urinário. Referente à etiologia, a principal responsável pelas infecções foi a Escherichia coli, acometendo 77,78\% dos casos, seguido de Streptococcus agalactiae e Enterococcus faecalis, ambos com 11,11\% de incidência.

A Tabela 2 representa o percentual de amostras com ITU que obtiveram alterações leucocitárias representadas no teste bioquímico com tira reagente e presença de nitrito urinário em comparação com os uropatógenos encontrados. Nas infecções por E. coli, duas amostras não apresentaram esterase leucocitária e uma não obteve nitrito positivo. Enquanto que nas infecções por $S$. agalactiae e E. faecalis, ambas apresentaram alteração leucocitária, porém sem presença de nitrito urinário.

Tabela 2. Relação entre a presença de esterase leucocitária e nitrito positivo com os micro-organismos encontrados nas amostras.

\begin{tabular}{lcc}
\hline Micro-organismos & Esterase leucocitária & Presença de nitrito \\
\hline Escherichia coli & $71,42 \%$ & $85,71 \%$ \\
Streptococcus agalactiae & $100 \%$ & $0 \%$ \\
Enterococcus faecalis & $100 \%$ & $0 \%$ \\
\hline
\end{tabular}

No teste de sensibilidade a antimicrobianos (TSA) foram testados dez antibióticos para as amostras contendo BGN, sendo eles a ceftriaxona, norfloxacino, ciprofloxacino, gentamicina, ampicilina, levofloxacino, nitrofurantoína, cefalotina, amicacina e cefazolina.

De acordo com o antibiograma, verificou-se que todas as amostras isoladas de E. coli foram sensíveis a ceftriaxona, gentamicina, nitrofurantoína e amicacina, e duas amostras mostraram resistência ao norfloxacino, ciprofloxacino, levofloxacino e ampicilina. A Figura 1 representa o resultado do TSA realizado para as amostras contendo E. coli. 


\section{Perfil de sensibilidade de Escherichia coli aos antimicrobianos}

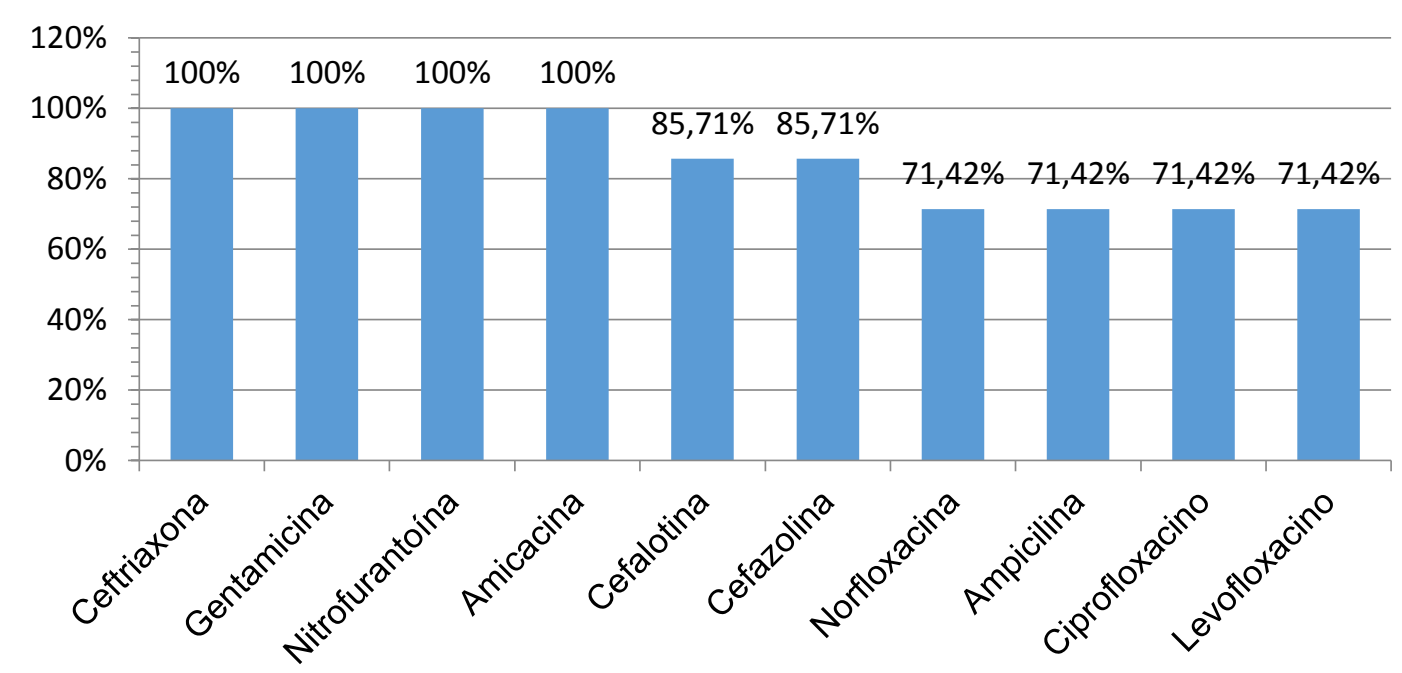

Figura 1: Teste de sensibilidade de bacilos Gram-negativos (Escherichia coli) aos antimicrobianos.

No TSA para E. faecalis, foram utilizados os antimicrobianos linezolide, ciprofloxacino, penicilina, levofloxacino, ampicilina, nitrofurantoína, vancomicina, norfloxacino e tetraciclina. Com exceção da tetraciclina, a qual a bactéria obteve sensibilidade intermediária, todos os antibióticos mostraram-se eficazes contra o micro-organismo.

Para a amostra contendo Streptococcus agalactiae, testou-se a atividade da ampicilina, levofloxacino, linezolide e penicilina. Para todos os antibióticos a amostra obteve sensibilidade.

\section{Discussão}

As complicações maternas são, de forma geral, secundárias ao dano tecidual causado por endotoxinas bacterianas, ocorrendo principalmente nos quadros de pielonefrite (NEAL, 2008). Outras complicações têm sido associadas à infecção urinária, incluindo hipertensão/préeclâmpsia, anemia, corioamnionite e endometrite (DUARTE et al., 2008; RUSTVELD et al., 2008).

O fluxo urinário comprometido, mecânica ou funcionalmente, é a condição básica mais comum que predispõe os pacientes a ITUs. A expansão do útero durante a gravidez causa redução na capacidade urinária da bexiga e uma pressão extrema sobre os ureteres (FALCÃO e LEONE, 2000).

Com uma incidência de $18 \%$ de casos com infecção urinária no grupo estudado, este número mostrou-se acima dos dados encontrados na literatura, a qual relata que infecções do trato urinário são acometidas em cerca de 10 a $12 \%$ das gestações de acordo com Jacociunas e Picoli (2007) e entre 5 a $10 \%$ relatado por Duarte et al. (2002).

Segundo Heilberg e Schor (2003), a incidência de bacteriúria em gestantes aumenta em relação ao número prévio de gestações. Todavia, o estudo em questão mostra-se em desacordo com esta afirmativa, visto que a maior parte das infecções acometeram gestantes primigestas. Da mesma forma ocorreu em estudo realizado por Duarte et al., (2002), no qual as infecções urinárias em pacientes primigestas prevaleceram $(51,5 \%)$. Portanto, fica evidente a diversificação de informações na literatura relacionando paridade com a incidência de infecções do trato urinário.

Em relação a idade gestacional, observou-se maior acometimento das infecções no terceiro trimestre da gestação, o que pode ser explicado por Varisco (2008) devido as alterações 
fisiológicas que ocorrem no trato urinário durante a gestação, tornando-se mais evidentes no segundo e, principalmente no terceiro trimestre. De acordo com Scarpa et al. (2006), está associada à pressão exercida pela cabeça fetal sobre a bexiga, com consequente redução da capacidade vesical.

Bacteriúria assintomática é a presença de bactérias na urina na ausência de ITU, geralmente não necessita de tratamento, à exceção da mulher grávida. Em gestantes, todos os casos de bacteriúria assintomática devem ser tratados, pois essas pacientes desenvolvem mais frequentemente infecções dos rins, que são potencialmente danosas e podem levar ao parto prematuro do bebê e hospitalização da gestante (VARISCO, 2008).

A prevalência de bacteriúria assintomática entre as gestantes foi de $10 \%$, da mesma forma como relatado por Heilberg e Schor (2003), o qual aponta ainda que pode ser observada do início da gestação ao terceiro trimestre e 25 a $57 \%$ destas bacteriúrias, quando não tratadas, podem evoluir para infecção sintomática, inclusive pielonefrite, devido à dilatação fisiológica do ureter e pelve renal facilitando o refluxo, há também o risco de ocorrer necrose papilar

As transformações anatômicas e fisiológicas que ocorrem no trato urinário durante a gravidez facilitam a evolução de infecções urinárias assintomáticas para sintomáticas. A compressão extrínseca dos ureteres e a redução da atividade peristáltica provocada pela progesterona provocam dilatação progressiva das pelves renais e ureteres. Essas mudanças, junto com o aumento do débito urinário, levam à estase urinária. A estase ainda é favorecida pela diminuição do tônus vesical, com subsequente aumento da capacidade da bexiga e seu esvaziamento incompleto, facilitando o refluxo vesicoureteral e pielonefrites. Além disso, o rim perde sua capacidade máxima de concentrar a urina, reduzindo sua atividade antibacteriana, e passa a excretar quantidades maiores de glicose e aminoácidos, fornecendo meio apropriado para a proliferação bacteriana (DUARTE et al., 2002).

Para o diagnóstico clínico das ITUs durante a gravidez, alguns sintomas da infecção são difíceis de caracterizar, visto que, geralmente durante a gestação, alguns deles podem estar presentes, a exemplo da polaciúria (DUARTE et al., 2008). Para a triagem de casos agudos suspeitos de ITU, as fitas reagentes são notadamente úteis, principalmente em nível ambulatorial ou no consultório. As fitas detectam esterase leucocitária (indicativa de piúria) ou atividade redutora de nitrato (HEILBERG e SCHOR, 2003).

O teste do nitrito pode apresentar resultados falso-positivos, como ocorreu em um caso apresentado no estudo, isto pode ser explicado quando a amostra de urina estiver contaminada por germes vaginais ou a urina for concentrada, uma vez que segue princípios colorimétricos (DUARTE et al., 2008). Pode ainda ocorrer quando o exame não for realizado com amostras recém-coletadas, devido à multiplicação das bactérias contaminantes, que logo produzem quantidades mensuráveis de nitrito (SILVA et al., 2005).

Embora os resultados falso-positivos sejam extremamente raros, frequentes são os resultados falso-negativos. O teste é excelente para detecção de enterobactérias, porém muito precária para o rastreio de estafilococos e estreptococos (SILVA et al., 2005), como pôde ser observado nas amostras acometidas por Streptococcus agalactiae e Enterococcus faecalis.

Quanto ao teste de esterase leucocitária, também podem ser obtidos resultados falsopositivos para infecção urinária (SATO et al., 2005), já que a presença de piúria traduz apenas a existência de uma inflamação, podendo ser o resultado de uma contaminação da urina por vulvovaginites ou uretrites (FIGUEIREDO et al., 2012).

Dentro do espectro bacteriano que pode causar ITU em gestantes, a $E$. coli é o uropatógeno mais comum, responsável por aproximadamente $80 \%$ dos casos (DUARTE et al., 2008), sendo observado em $77,78 \%$ das gestantes no estudo em questão. Este micro-organismo pertence à flora normal do intestino humano e pode contaminar, colonizar e, subsequentemente, causar infecções extraintestinais, sendo um dos principais agentes etiológicos de septicemias, meningites e infecções do trato urinário (KAZMIRCZAC et al., 2005). 
Outros aeróbios Gram-negativos também podem causar infecção urinária durante a gravidez, como Klebsiella pneumoniae, Proteus mirabilis, Enterococcus sp e Enterobacter sp (FIGUEIREDO et al., 2012). Bactérias gram-positivas também causam ITU apesar da sua baixa incidência, destacando-se o Staphylococcus saprophyticus, Streptococcus agalactiae e outros estafilococos coagulase negativos (DUARTE et al., 2008).

Os enterococos são bactérias gram-positivas aeróbias facultativas que colonizam a microbiota do trato gastrointestinal e do sítio anatômico genital. Atualmente sua presença é notável em infecções urinárias, infecções de sítio cirúrgico e bacteremias, possuem 16 espécies descritas, sendo que há predominância de duas a E. faecalis e E. faecium (SOUZA et al., 2012).

$S$. agalactiae é um estreptococo do grupo B (EGB), e faz parte da microbiota de membranas mucosas, colonizando principalmente os tratos intestinal e geniturinário. A grande relevância médica deste micro-organismo está na contaminação de neonatos, ocasionando quadros graves de septicemia, pneumonia e meningite (BORGER et al., 2005). Durante a gravidez, a bacteriúria por EGB, mesmo que não significativa, está associada a inúmeras complicações como ruptura prematura de membranas de pré-termo, parto prematuro e sepses neonatal precoce. Desta forma, todas as mulheres com bacteriúria por essas bactérias durante a gravidez, devem ser tratadas no momento do diagnóstico, bem como submetidas à antibioticoterapia profilática intraparto, de forma a prevenir a infecção neonatal (FIGUEIREDO et al., 2012).

No teste de sensibilidade aos antimicrobianos, verificou-se que duas amostras isoladas de E. coli apresentaram resistência aos antibióticos norfloxacino, ciprofloxacino, levofloxacino e ampicilina. Diversos pesquisadores têm chamado à atenção para o crescimento lento da resistência da E. coli a norfloxacino, ciprofloxacino e outras quinolonas, o que parece estar, em parte, relacionado ao uso frequente desses antimicrobianos na profilaxia de infecções e na terapia de ITUs (AMADEU et al., 2009).

Nos antibiogramas para as amostras com Streptococcus agalactiae e Enterococcus faecalis, ambas obtiveram boa sensibilidade para os antimicrobianos testados. Além disso, a CLSI - Clinical and Laboratory Standards Institute (2005) relata, que o teste de sensibilidade das penicilinas e outros $\beta$-lactâmicos para tratamento de infecções por Streptococcus agalactiae não são necessários para fins clínicos e não precisam ser realizados rotineiramente, uma vez que para a vancomicina, não têm sido identificadas cepas resistentes.

$\mathrm{O}$ uso de antibióticos durante a gravidez é muito singular. Medicamentos utilizados com segurança na prática clínica diária não devem ser usados nas gestantes, a exemplo do cloranfenicol e sulfonamidas, além de tetraciclinas, quinolonas e sulfas no primeiro trimestre. A escolha do antibiótico deve levar em conta, além da sensibilidade das bactérias, outros fatores como a facilidade de obtenção pela paciente, a sua tolerabilidade, a comodidade de sua posologia, custo e toxicidade. Além disso, os antibióticos só devem ser prescritos quando seus efeitos benéficos sobrepujarem significativamente os seus possíveis riscos (FIGUEIRÓ-FILHO et al., 2009).

O tratamento da bacteriúria assintomática é controverso, porém, a única indicação absoluta de tratamento é na gravidez, devido ao risco da bacteriúria predispor à pielonefrite e necrose papilar. Os antimicrobianos que podem ser utilizados com segurança na gravidez são cefalexina, ampicilina, amoxacilina e nitrofurantoína. Com o ciprofloxacino, os riscos não podem ser descartados (HEILBERG e SCHOR, 2003).

\section{Conclusão}

O elevado número de infecções do trato urinário que acomete gestantes do município de Missal/PR, especialmente as formas assintomáticas, reforçam a necessidade do diagnóstico 
precoce e tratamento adequado, a fim de evitar a evolução de cistites para pielonefrites e a ocorrência de complicações perinatais, como o trabalho de parto e o parto prematuro.

O estudo epidemiológico dos uropatógenos e do perfil da sensibilidade aos antimicrobianos são aspectos que merecem atenção, pois podem ser significantemente diferentes de acordo com a localidade. Além disso, a vigilância constante do aparecimento de novas cepas bacterianas resistentes é de grande importância, pois estas podem causar transtornos ao profissional médico na tentativa de combatê-las.

O perfil de suscetibilidade das gestantes frente à ocorrência de ITUs contribui para o entendimento da reduzida defesa do hospedeiro neste período. Como medida de prevenção, o ideal seria que todas as gestantes realizassem o acompanhamento pré-natal com a realização de urocultura em cada trimestre da gestação, evitando assim, problemas futuros comprometendo a saúde da mãe e do feto.

O reconhecimento destes fatores poderá futuramente contribuir para a elaboração de programas preventivos que visem melhorar a qualidade da atenção oferecida durante o pré-natal pelos profissionais da saúde.

\section{Referências}

AMADEU, A. R. O. R. M.; SUCUPIRA, J. S.; JESUS, R. M. M.; ROCHA, M. L. P. Infecções do trato urinário: análise da frequência e do perfil de sensibilidade da Escherichia coli como agente causador dessas infecções. RBAC - Revista Brasileira de Análises Clínicas, vol. 41(4): 275-277, 2009.

BORGER, I. L.; OLIVEIRA, R. E. C.; CASTRO, A. C. D; MONDINO, S. S. B. Streptococcus agalactiae em gestantes: prevalência de colonização e avaliação da suscetibilidade aos antimicrobianos. Revista Brasileira de Ginecologia e Obstetrícia. 27(10): 575-9, 2005.

CARVALHO, F. J. W. Envelhecimento do aparelho genito-urinário. Tratado de geriatria e gerontologia. Rio de Janeiro: Guanabara Koogan, 1252p. Cap. 50, p. 426-429, 2002.

CLSI - Clinical and Laboratory Standards Institute. Normas de desempenho para testes de sensibilidade antimicrobiana. $\mathbf{1 5}^{\circ}$ suplemento informativo - CLSI document M100-S15 (ISBN 1-56238-556-9). Pennsylvania 19087-1898 USA, 2005.

CONDE-AGUDELO, A.; VILLAR, J.; LINDHEIMER, M. Maternal infection and risk of preeclampsia: systematic review and metaanalysis. American Journal of Obstetrics and Gynecology. 198(1):7-22, 2008.

DALBOSCO, V.; SROUGI, M.; DALL'OGLIO, M. Infecções do Trato Urinário. Revista Brasileira de Medicina, 60. (6): 320-336, 2003.

DUARTE, G.; MARCOLIN, A. C.; GONÇALVES, C. V.; QUINTANA, S. M.; BEREZOWSKI, A. T.; NOGUEIRA, A. A.; CUNHA, S. P. Infecção Urinária na Gravidez: Análise dos Métodos para Diagnóstico e do Tratamento. Ribeirão Preto: Revista Brasileira de Ginecologia e Obstetrícia. 24(7):471-7, 2002.

DUARTE, G.; MARCOLIN, A. C.; QUINTANA, S. M.; CAVALLI, R. C. Infecção urinária na gravidez. Ribeirão Preto: Revista Brasileira de Ginecologia e Obstetrícia. 30(2):93-100, 2008. 
DUARTE, G.; QUINTANA, S. M.; El BEITUNE, P.; MARCOLIN, A. C.; CUNHA, S. P. Infecções gênito-urinárias na gravidez. In: ALVES FILHO, N.; CORRÊA, M. D.; ALVES, Jr J. M. S.; CORRÊA, Jr M. D.; editores. Perinatologia básica. 3a ed. Rio de Janeiro: Guanabara Koogan, p.129-41, 2006.

FALCÃO, M. C.; LEONE, C. R. Urinary tract infetion in full-term newborn infantis: risk factor analysis. Revista do Hospital das Clínicas da Faculdade de Medicina Universidade de São Paulo. V.55 (1): 9-16, 2000.

FIGUEIREDO, A.; GOMES, G.; CAMPOS, A. Infecções urinárias e gravidez - diagnóstico, terapêutica e prevenção. Acta Obstet Ginecol Port. 6(3):124-133, 2012.

FIGUEIRÓ-FILHO, E. A.; BISPO, A. M. B.; VASCONCELOS, M. M.; MAIA, M. Z.; CELESTINO, F. G. Infecção do trato urinário na gravidez: aspectos atuais. FEMINA Vol. $37 \mathrm{n}^{\circ}$ $3,2009$.

GUPTA, K.; HOOTON, T. M.; STAMM, W. Antimicrobial resistence and the Management of Uncomplicated Community-Acquired Urinary Tract Infection. Ann. Intern. Med., 145: 41-50, 2001.

HEILBERG, I. T.; SCHOR, N. Abordagem diagnóstica e terapêutica na infecção do trato urinário - ITU. Revista da Associação Médica Brasileira. SP, v. 49, 2003.

JACOCIUNAS, L. V.; PICOLI, S. U. Avaliação de Infecção Urinária em Gestantes no Primeiro Trimestre de Gravidez. Revista Brasileira de Analises Clínicas. vol. 39(1): 55-57, Porto Alegre, 2007.

KAZMIRCZAK, A.; GIOVELLI, F. H.; GOULART, L. S. Caracterização das Infecções do Trato Urinário Diagnosticadas no Município de Guarani das Missões - RS. Guarani das Missões: Revista Brasileira de Analises Clínicas. vol. 37(4): 205-207, 2005.

MCDERMOTT, S.; CALLAGHAN, W.; SZWEJBKA, L.; MANN, H.; DAGUISE, V. Urinary tract infections during pregnancy and mental retardation and developmental delay. Obstet Gynecol, 96(1):113-9, 2000.

MCPHERSON, R. A.; PINCUS, M. R. Diagnósticos clínicos e tratamento por métodos laboratoriais de Henry. 21 ed. Barueri, SP: Manole, 2012.

NEAL, D. E. Jr. Complicated urinary tract infections. Urol Clin North Am. 35(1):13-22, 2008.

RUSTVELD, L. O.; KELSEY, S. F.; SHARMA, R. Association between maternal infections and preeclampsia: a systematic review of epidemiologic studies. Matern Child Health J., 12(2):223-42, 2008.

SATO, A. F.; SVIDZINSKI, A. E.; CONSOLARO, M. E. L.; BOER, C. G. Nitrito urinário e infecção do trato urinário por cocos gram-positivos. J Bras Patol Med Lab. v. 41 n. 6 p.397404, 2005. 
SCARPA, K. P.; HERRMANN, V.; PALMA, P. C. R.; RICETTO, C. L. Z.; MORAIS, S. Prevalência de sintomas urinários no terceiro trimestre da gestação. Revista da Associação Médica Brasileira. 52(3): 153-6, 2006.

SILVA, C. H. P. M.; LINS, A. P.; SOUZA, D. R.; CRUZ, C. S. O.; BERGAMASCHI, G. C. Desenvolvimento e utilização de conservante químico em amostras de urina para análises microbiológicas (urocultura) e rotina (E.A.S.) Revista Brasileira de Análises Clínicas, vol. 37(3): 137-147, 2005.

SOUZA, M. A.; RIBEIRO, L. C. M.; PRIMO, M. G. B.; SIRICO, S. C. A.; GUILARDE, A. O.; BATISTA, L. J. A. Enterococo resistente à vancomicina em um hospital universitário no centrooeste do Brasil. Rev Patol Trop. Vol 41, 2012.

VARISCO, T. E. Prevalência de infecções urinárias em gestantes atendidas na Unidade Básica de Saúde Aurora no município de Campo Bom. Trabalho de conclusão do curso de Ciências Farmacêuticas. Centro Universitário Feevale. Novo Hamburgo, 2008. 